provided for the assertions described above, we remain uncertain about what they are based on. Since these views are part of the consensus statement, which presumably will be used as a benchmark for clinical practice, for second opinions, and so on, this is a serious matter. In its present form the consensus statement is profoundly misleading in its comments on adolescents and we urge that it be revised in the light of current research and informed clinical opinion.

GARRALDA, E. \& AnSWORTH, P. (1987) In Working with Troubled Adolescents (ed. Coleman), pp. 169-196. London: Academic Press.

Gillberg, C., Hellaren, L. \& Glllbert, C. (1993) Psychotic disorders diagnosed in adolescents. Outcome at age $\mathbf{3 0}$ years. Journal of Child Psychology and Psychiatry, 34, 1173-1185.

Green, W. H., PADron-Gayol, M., HARdesty, A. S., et al (1992) Schizophrenia with childhood onset. Journal of the American Academy of Child and Adolescent Psychiatry, 31, 968-976.

Werry, J. S., MCClellan, J. M. \& CHARD, L. (1991) Childhood and adolescent schizophrenia, bi-polar, and schizo-affective disorders: a clinical and outcome study. Journal of American Academy of Child and Adolescent Psychiatry, 30, 457-465.

Young People's Unit

Royal Edinburgh Hospital

Edinburgh EHIO $5 \mathrm{HF}$

DAVID WIIL

ROBERT M. WRATE

The Young People's Unit Newcastle General Hospital

Highfield Adolescent Unit Warneford Hospital Oxford

Shuryah Bhate Peter TAYLOR

TONY JAMES

Adolescent Unit

Hollymoor Hospital

Birmingham

DAVID ROTHERY

ANDREW ClaRK

\section{Epilepsy in Down's syndrome}

SIR: McVicker et al (BJP, April 1994, 164, 528532) describe the associated features of epilepsy in adults with Down's syndrome. In a similar study of a hospital population of people with Down's syndrome in Bristol, we found some markedly similar as well as contrasting results.

In a population of 43 patients with genetically proven full trisomy 21 ( 23 women, 20 men, mean age 51.5 years), $11(26 \%)$ had epilepsy, which is the same percentage as in McVicker's hospital subsample. Other similarities were the dramatic increase in prevalence of epilepsy with age, being $38 \%$ for those over 50 years and only $6 \%$ for those under 50 (c.f. McVicker's $46 \%$ and $7 \%$ ) and the strong association between epilepsy and dementia, with eight of the ten epileptics over 50 years dementing, and only two patients showing marked functional decline without evidence of epilepsy.

In contrast to McVicker, only 2 out of 11 epileptics $(18 \%)$ had clearly secondary generalised seizures (McVicker reported the "majority" to have them) and only $6(55 \%)$ showed paroxysmal features on electroencephalography (c.f. McVicker's $80 \%$ ). The commonest seizure type was generalised tonic-clonic, but notably three had myoclonic, one atonic, and two a mixture of absence and tonicclonic seizures. This mix of seizure type explained our finding that, as in McVicker's study, sodium valproate was the most commonly used antiepileptic medication. I would therefore question the McVicker group's assertion that, on the basis of seizure type, carbamazepine is in general a more logical choice of anti-epileptic.

In the Bristol study, neurological examination was done on all patients except two who refused. A striking feature was the high prevalence of clinically increased muscle tone (19 out of $43(44 \%)$ ) in a group that is typically hypotonic. Prevalence increased with age, with no patients below the age of 40 years and 11 of the 14 over 60 years $(78 \%)$ showing increased tone. Hypertonicity appeared to be associated with dementia and epilepsy: only one dementing and one epileptic patient had normal muscle tone, and all patients with both dementia and epilepsy had increased tone. This raises the possibility that increasing muscle tone is an important precursor of the dementia complex in Down's syndrome. A prospective study with more precise measurement of muscle tone is needed to evaluate this hypothesis.

Chris Speller

Knowle Clinic

Bristol BS4 2UH

SUSAN JOHNSTON

Lincoln District Learning Disability Service

St James' Hospital

Sunita Kanagaratnum

Southsea

Defeating depression in Zimbabwe

SIR: Abas et al (BJP, March 1994, 164, 293-296) describe how mental health research and service 
delivery can be coordinated at a regional level, taking into account regional priorities and cultural factors. Their emphasis on the community is a refreshing change from the top-down approach of multinational studies whose data seem to have a place only in academic journals and psychiatric institutes rather than the lives of ordinary patients and primary health care providers.

The authors suggest that kufungisisa, or thinking too much, encapsulates the syndrome of depression. However, in our study (in preparation) of 110 patients with conspicuous psychiatric morbidity presenting to general nurses and traditional care providers, this term has been used as a generic term for common mental disorder in over $80 \%$ of cases. The term describes both a phenomenon and a causal model of illness. 'Etic' evaluation with the Revised Clinical Interview Schedule shows that while kufungisisa as a cause is significantly related to etic 'caseness' criteria, it is not specifically related to either depression or anxiety. As a phenomenon, 'thinking too much' seems to be conceptually related to worry. The suggestion that kufungisisa is not related to spiritual causes (as opposed to madness) depends on which care provider is the respondent. Thus, traditional care providers were as likely to perceive a spiritual cause for patients with kufungisisa as for those without, while nurses never considered a spiritual cause for any of their patients. There is not yet evidence to suggest that kufungisisa is equivalent to the Euro-American category of depression.

It is perhaps early to suggest that a model of tackling depression developed in the most urbanised part of Zimbabwe can be generalised to the rural areas, where mental health services are virtually non-existent, and where traditional care providers remain the mainstay of primary mental health care. Even in Harare, up to three-quarters of patients with conspicuous psychiatric morbidity are consulting traditional care providers. A successful intervention programme must take into account their role, concepts and treatment methods, and seek ways of complementing biomedical and traditional health care.

Abas et al have taken more pains in eliciting local views and priorities than many international researchers; only if their message of community-based research is adopted will the knowledge of mental health be culturally valid and understood by the 'front-line' primary health workers.

Department of Psychiatry

University of Zimbabwe

\section{Glucocorticoids, serotonin and mood}

SIR: Dinan has provided a reminder of the possible importance of glucocorticoids in the genesis of depression (BJP, March 1994, 164, 365-372) and stressed that glucocorticoids may produce changes in central monoaminergic function. That glucocorticoids modulate brain monoamine function (particularly brain 5-HT function) has been confirmed in experiments, in both rodents and man (Young et al, 1994). Hypercortisolaemia has been widely reported in depressive disorders as well as other psychiatric disorders (Christie et al, 1986). The question therefore arises as to the possible role of hypercortisolaemia in the pathophysiology of depression.

As Dinan states, there is evidence that in depression blunted 5-HT responses occur in patients who also have higher cortisol levels; this finding suggests that hypercortisolaemia may cause the neurotransmitter abnormalities which give rise to the clinical syndrome. However, high-dose glucocorticoids have been shown to elevate mood briefly in severe depression (Goodwin et al, 1992) and glucocorticoids down-regulate the function of presynaptic $5-\mathrm{HT}_{1 \mathrm{~A}}$ receptors (Young et al, 1994). This action is shared with antidepressant drugs and electroconvulsive shock; thus, it has been suggested it mediates the mood-elevating effects of glucocorticoids (Young et al, 1994). This apparent contradiction may be due to the fact that the hypercortisolaemia of depression is a complex phenomenon which may involve hypothalamic releasing factor hypersecretion, adrenal hypersensitivity to adrenocorticotrophic hormone, pituitary resistance to glucocorticoid feedback, pituitary hypersensitivity to releasing factors, and neural feedback resistance (Sapolsky, 1992).

Hypercortisolaemic depressed patients may be subject to a number of complex neurobiological processes, some of which may be distinct from those effects due to elevated glucocorticoids alone. The key to understanding the genesis of depression may lie in these differing processes and there is a pressing need for further research, both laboratory and clinical, on this subject.

Christie, J. E., Whalley, L. J., Dick, H., et al (1986) Raised plasma cortisol levels a feature of drug free psychotics and not specific for depression. British Journal of Psychiatry, 148, 58-65.

Goodwin, G. M., MuIR, W. J., SeckL, J. R., et al (1992) The effects of cortisol infusion upon hormone secretion from the anterior pituitary and subjective mood in depressive illness and controls. Journal of Affective Disorders, 26, 73-84.

SAPOLSKY, R. M. (1992) Stress, the Aging Brain and Mechanisms of Neuron Death. Cambridge, Massachusetts: MIT Press. 